\title{
Umbilical cord blood transplantation
}

Hong Hoe Koo, MD', Hyo Seop Ahn, MD²

${ }^{1}$ Department of Pediatrics, Samsung Medical Center, Sungkyunkwan University School of Medicine, Seoul, ${ }^{2}$ Department of Pediatrics, Cancer Research Institute, Seoul National University College of Medicine, Seoul, Korea

Received: 21 March 2012, Accepted: 19 April 2012 Corresponding author: Hyo Seop Ahn, MD, PhD Division of Hematology/Oncology, Department of Pediatrics, Cancer Research Institute, Seoul National University College of Medicine, 101 Daehak-ro, Jongno-gu, Seoul 110744, Korea

Tel: +82-2-2072-3570, Fax: +82-2-743-3455,

E-mail: hsahn@snu.ac.kr

Copyright $@ 2012$ by The Korean Pediatric Society
Since the first umbilical cord blood transplantation (CBT) in 1998, cord blood (CB) has now become one of the most commonly used sources of hematopoietic stem cells for transplantation. CBT has advantages of easy procurement, no risk to donor, low risk of transmitting infections, immediate availability and immune tolerance allowing successful transplantation despite human leukocyte antigen disparity. Several studies have shown that the number of cells transplanted is the most important factor for engraftment in CBT, and it limits the wide use of CB in adult patients. New strategies for facilitating engraftment and reducing transplantation-related mortality are ongoing in the field of $\mathrm{CBT}$ and include the use of a reduced-intensity conditioning regimen, double-unit $\mathrm{CBT}$, ex vivo expansion of $\mathrm{CB}$, and co-transplantation of $\mathrm{CB}$ and mesenchymal stem cells. Recently, the results of two international studies with large sample sizes showed that CB is an acceptable alternative source of hematopoietic stem cells for adult recipients who lack human leukocyte antigen-matched adult donors. Along with the intensive researches, development in banking process of $\mathrm{CB}$ will amplify the use of $\mathrm{CB}$ and offer the chance for cure in more patients.

Key words: Umbilical cord blood, Transplantation, Hematopoietic stem cells

This is an open-access article distributed under the terms of the Creative Commons Attribution Non-Commercial License (http://creativecommons.org/licenses/by$\mathrm{nc} / 3.0 /$ ) which permits unrestricted non-commercial use, distribution, and reproduction in any medium, provided the original work is properly cited.

\section{Introduction}

Allogeneic hematopoietic stem cell transplantation (HSCT) is the only curative option for many diseases, such as hematologic malignancies, immune deficiency syndrome, and bone marrow (BM) failure. A human leukocyte antigen (HLA)-matched sibling donor is considered the best hematopoietic stem cell (HSC) donor; however, only approximately $30 \%$ of the patients can receive transplantation from an HLA-matched sibling donor. In the absence of such a donor, the search for an unrelated volunteer adult donor is currently performed and more than 14 million potential unrelated adult donors are registered with the unrelated-donor registries worldwide.
However, the HLA-matched unrelated donors are found for only approximately $50 \%$ of the patients. Additionally, the search and procurement process for adult donors can take weeks or months; consequently, cord blood (CB) is becoming an increasingly attractive alternative to HLA-matched peripheral blood progenitor cells (PBPCs) or BM.

\section{History of cord blood transplantation (CBT)}

Since the CB was found to have sufficient progenitor cells for clinical hematopoietic reconstitution, researches showed that $\mathrm{CB}$ could be an alternative HSC source ${ }^{1)}$. Thereafter, studies about 
collection, transportation, optimal cryopreservation of $\mathrm{CB}$, and the viability of CB after thawing have been conducted. In 1988, the first CBT was performed in a patient with Fanconi anemia $(F A)^{2}$. Furthermore, in 1991, CB was successfully transplanted from an HLA-matched sibling to a child with acute lymphoblastic leukemia, and in 1993, CB was transplanted from an unrelated donor for the first time ${ }^{3}$. CB, which was previously discarded after birth, has emerged as a valuable stem cell source and has led to remarkable progress in the field of allogeneic HSCT. The progress in the field of CBT aroused huge interest in the establishment and development of CB banks worldwide. These banks play an important role in the CBT process. In 1998, the Netcord group was created to establish good practices in $\mathrm{CB}$ storage, to facilitate donor search, to improve the quality of grafts, and to establish procedures for bank accreditation. At present, it is estimated that more than $400,000 \mathrm{CB}$ units are available for transplantation in more than $100 \mathrm{CB}$ banks in many countries.

\section{Characteristics of CB}

Although CB contains one log fewer nucleated cells than BM or mobilized PBPC, it has a higher primitive HSC content and higher proliferative potential than either BM or mobilized PBPC. Therefore, CB may serve as a reliable source for HSCT despite the limited cell number.

The incidence of graft-versus-host disease (GVHD) is less than expected given the degree of HLA disparity in CBT. The exact reasons for the relatively low incidence of GVHD are unknown, but may result from the functional immaturity of infused lymphocytes, including decreased cytotoxicity, an altered cytokine profile, decreased HLA expression and increased regulatory T-cells ${ }^{4}$. Despite a low incidence of GVHD in CBT, graft-versus-leukemia effect is preserved, which may be associated with natural killer cells in $\mathrm{CB}^{5}$.

$\mathrm{CB}$ offers many advantages such as easy procurement with no risk for the donor, reduced risk of transmitting infections, and rapid availability of cryopreserved cell. CBT also permits transplantation in the absence of full HLA compatibility between donor and recipient. The disadvantages of CBT are the higher rate of graft failure, delayed hematopoietic recovery, the risk of genetic disorder transmission, and the inability to further obtain stem cells or donor lymphocyte infusion ${ }^{6}$.

\section{Clinical outcomes of CBT}

\section{1. $C B T$ in children}

The International Bone Marrow Transplant Registry and
Eurocord Transplant Group published the results of CBT from related donors, for which the 2-year survival rate was found to be $60 \%$. In a study for children including 113 recipients of a related CBT and 2,052 recipients of related BM, CBT was found to be associated with delayed hematopoietic recovery and reduced acute and chronic GVHD. The 3-year survival rate was $64 \%$ in the recipients of $\mathrm{CB}$ and $66 \%$ in the recipients of $\mathrm{BM}$, respectively. The relapse rate was same despite lower risk of GVHD in CBT than in bone marrow transplantation ${ }^{7}$. Overall, the data suggest that $\mathrm{CB}$ is as effective as $\mathrm{BM}$ as a source of HSC for children who receive transplants from HLA-identical siblings. This study was the basis for advocating the use of mismatched CBT and triggered the development of unrelated CB banks. In the unrelated donor transplant setting, CBT provides several advantages such as short time to transplant, rapid availability, tolerance to 1-2 HLA-mismatch, and a lower risk of GVHD. Cell dose and HLA compatibility are the major factors influencing the outcome after CBT. In a recent study, the outcomes of 503 children with acute leukemia and transplanted with $\mathrm{CB}$ were compared with outcomes of $282 \mathrm{BM}$ recipients. In comparison with allele-matched BM transplants (HLA-A, B, C, DRB1; 8/8), the transplantationrelated mortality (TRM) rates were higher after transplantation with 1 or 2-antigen HLA-mismatched CB and lower after transplantation with HLA-matched CB (Fig. 1A). The 5-year leukemia-free survival rate was similar between transplants of 1 or 2-antigen HLAmismatched $\mathrm{CB}$ and transplants of allele-matched BM. Furthermore, the 5-year leukemia-free survival was higher after transplants of HLA-matched $\mathrm{CB}^{8)}$. These data suggest that better HLA matching and higher cell doses significantly improve the outcomes (Fig. 1B). Therefore, greater investment in large-scale banking is required to increase HLA diversity and to search optimal CB unit.

\section{CBT in adults}

Cell dose is well recognized as a factor that influences outcomes following CBT. In particular, a low cell dose is a problem in adults, for whom it is difficult to find a single unit with an adequate cell dose for proceeding to transplantation. Despite cell dose limitation in adult $\mathrm{CBT}$, a reduced incidence of GVHD in CBT may result in the reduced TRM in the recipients of CBT.

According to the study conducted by the Japan Cord Blood Bank Network, the results showed similar relapse rates, TRM, and overall survival rates between the recipients of $\mathrm{CB}$ and $\mathrm{BM}^{9}$. In a recent international retrospective analysis in adults with acute leukemia, $94 \%$ of the patients were transplanted with 1 or 2 antigenmismatched $\mathrm{CB}$ and TRM was higher than in the recipients of $8 / 8$ allele-matched PBPC or BM (Fig. 1C). However, the incidences of GVHD were lower in CB recipients than in the recipients of allele- 

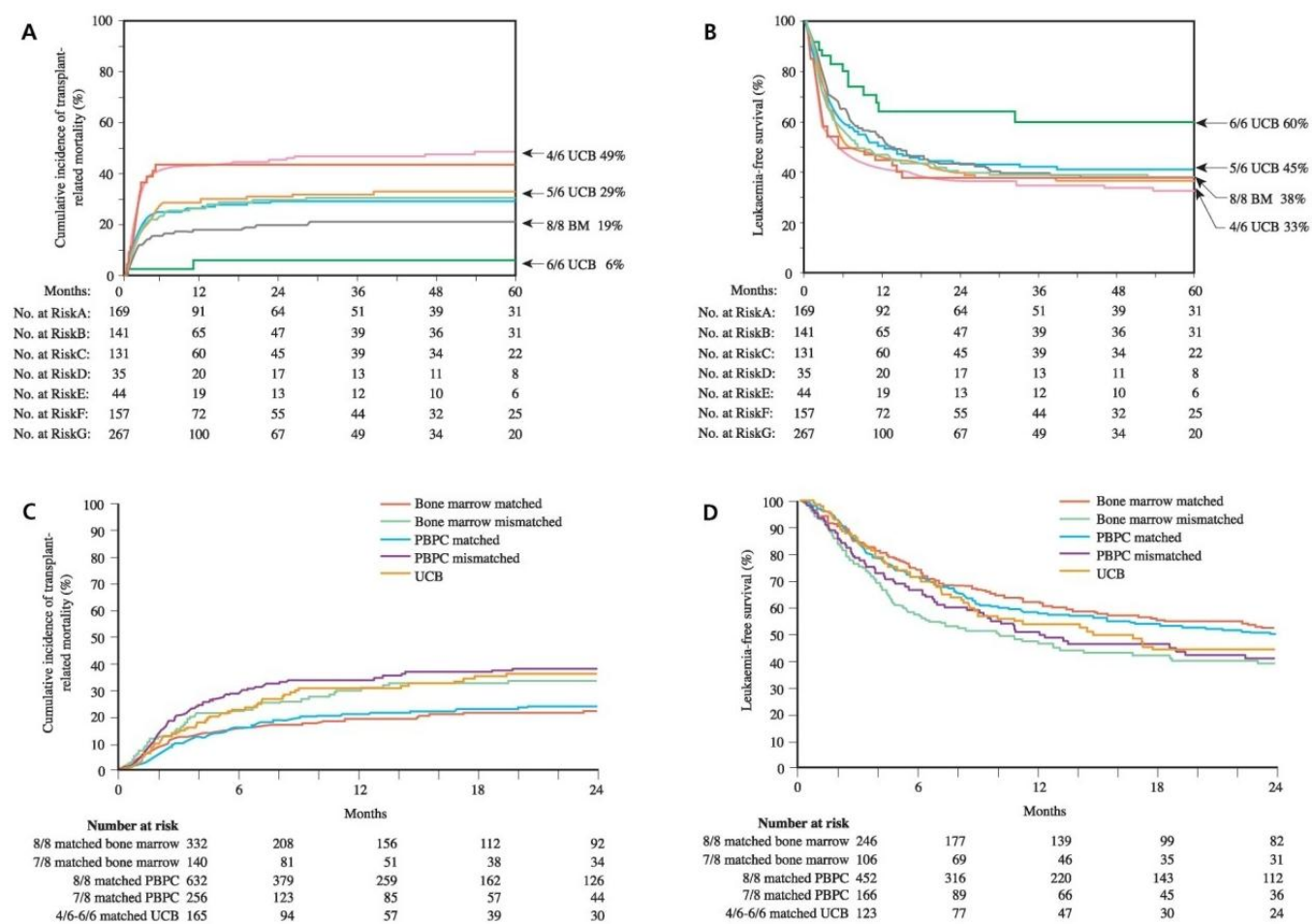

Fig. 1. The probabilities of transplantation-related mortality and leukemia free survival by hematopoietic stem-cell source and donor-recipient human leukocyte antigen matching in children and adults with acute leukemia (modified from Eapen M, et al. Lancet Oncol 2010;11:653-60, with permission of Elsevier) ${ }^{8,10)}$. (A) Transplantation-related mortality in children, (B) leukemia free survival in children, $(C)$ transplantation-related mortality in adults, and (D) leukemia free survival in adults. UCB, umbilical cord blood; BM, bone marrow; PBPC, peripheral blood progenitor cell.

matched PBPC or BM. As a result, the leukemia-free survival after CBT was comparable to that observed after allele-matched PBPC or BM transplantation (Fig. 1D). These data support the use of CB for adults when an HLA-matched unrelated adult donor is not available and when transplantation is urgent necessity ${ }^{10)}$.

\section{Clinical experiences of CBT in Korea}

In 1996, the first CBT was attempted in a child with severe aplastic anemia, resulting in graft failure. A child with acute lymphoblastic leukemia achieved successful engraftment after CBT in 1998, but outcome was unsuccessful. Subsequently, a child with acute biphenotypic leukemia was successfully transplanted with $\mathrm{CB}$ and remained leukemia free ${ }^{11)}$. However, CBT was not a realistic alternative to BM or PBPC transplantation in Korea until January 2003, when National Health Insurance started covering the cost of transplantation for children under the age of 16 years. Since then, the number of pediatric cases of CBT in Korea has increased dramatically. While 51 cases of CBT were performed for 7 years from 1996 to 2002, 49 cases were performed for one year of 2003. Many pediatric patients lacking a suitable donor can be transplanted and saved using CBT. In March 2004, the first successful double-unit
CBT was accomplished in Korea for a 14-year-old girl with acute myeloid leukemia ${ }^{12)}$. In January 2009, the Korean National Health Insurance policy began to cover all CB recipients, including adults without an appropriate familial donor. From 2001 to 2011, 352 cases of CBT have been performed through the KoreaCORD, of which 157 patients underwent double-unit CBT. A recent study reported the outcomes of 236 patients who underwent CBT, performed from 1996 to 2003 in 13 transplantation centers in Korea. The results showed that acute leukemia was the most frequent primary disease. The median times to neutrophil and platelet recovery were 18 and 45 days, respectively. Grade 2-4 acute GVHD and chronic GVHD developed in $41.1 \%$ and $36.1 \%$ of the cases, respectively. The 5-year overall survival and event-free survival rates were $47.5 \%$ and $36.9 \%$, respectively. Cytomegalovirus (CMV) disease developed in 45 patients (21\%) and was an adverse factor for survival. These data suggest that careful management for CMV is important in Korean children, whose CMV seroprevalence exceeds 90\%. Because an advanced disease status was found to be the most important risk factor for poor survival in the study, timely CBT is recommended when an appropriate BM or PBPC donor is not available ${ }^{13)}$. 


\section{Future directions}

\section{Double-unit CBT}

Attempts to increase $\mathrm{CB}$ graft cell dose have led to phase I clinical trials testing the safety of combined transplantation of 2 partially HLA-matched CB units. Barker et al. ${ }^{14)}$ studied 23 patients with high-risk hematologic malignancy who received $2 \mathrm{CB}$ units after myeloablative conditioning. The engraftment rate was $91 \%$. At day 60 after transplantation, engraftment was derived from a single donor in 16 of 18 patients, with 1 unit predominating in all patients by day 100. Neither nucleated or CD34+ cell doses nor HLA-matching predicted which unit would predominate. The incidence of grades III to IV acute GVHD was $13 \%$. These investigators concluded that transplantation of 2 partially HLA-mismatched CB units is safe and improves engraftment without increasing GVHD. It is speculated that the non-sustained unit may facilitate engraftment of the predominating unit by immunologic mechanisms despite the low cell dose in each unit ${ }^{14)}$.

Interestingly, the sustained hematopoiesis was derived from a single donor, which predominated as early as 3 weeks after transplantation. Although mechanisms that determine the fate of each donor are not yet known, Korean investigators have first reported that the number of post-thaw colony forming units of granulocyte-macrophage progenitors is the only significant factor predicting engraftment of the predominating unit ${ }^{15}$. Double-unit CBT may overcome the cell-dose barrier that limits the use of $\mathrm{CB}$ in many adults. In Korea, as of May 2011, 157 cases of double-unit CBT have been performed.

\section{Ex vivo expansion of $\mathrm{CB}$}

With the development of various expansion methods, the number of nucleated cells in $\mathrm{CB}$ could be expanded by as much as 400 -fold; however, ex vivo expanded $\mathrm{CB}$ failed to show durable engraftment ${ }^{16)}$. In a recent clinical trial, ex vivo expanded and unmanipulated $\mathrm{CB}$ fractions are combined for transplantation. Clinical data suggested that $\mathrm{CB}$ that has been subject to ex vivo expansion dose provide more rapid initial hematopoietic reconstitution, while unmanipulated $\mathrm{CB}$ is the source of the long-term, sustainable hematopoiesis ${ }^{17)}$. $E_{X}$ vivo expansion technologies are under investigation to inhibit the differentiation of progenitor cells and to facilitate engraftment.

\section{Co-transplantation of CB and mesenchymal stem cells} (MSCs)

MSCs are known to have the properties of tissue regeneration and immnosuppression ${ }^{18)}$. MSCs have been suggested to support the microenvironment of $\mathrm{BM}$, which is injured by conditioning regimen ${ }^{19)}$. In addition, immunosuppressive potential of MSCs may provide protection from immune-mediated injury to $\mathrm{HSC}$ in $\mathrm{CB}^{20}$. Therefore, co-transplantation of CB and MSCs is under investigation in an attempt to overcome the engraftment delay associated with $\mathrm{CBT}^{21}$. MSCs can be isolated from BM, CB, Wharton jelly, and adipose tissues. Clinical trials have been reported using MSCs from haploidentical donor. In addition, promising results, which cotransplantation of third-party CB-derived MSCs may enhance the engraftment of $\mathrm{CB}$, are first reported by Korean investigators ${ }^{22)}$. However, randomized trials are required to confirm the effects of MSCs on enhancing the engraftment of HSC.

\section{CBT after reduced-intensity conditioning (RIC)}

The development of RIC regimens allowed the treatment of older patients and those with associated comorbid conditions. The results from RIC CBT series show a shortened time to engraftment with TRM rates that generally do not exceed those seen with myeloablative $\mathrm{CBT}^{233}$. Although longer follow-up is needed, there does not seem to be a convincing trend toward an increase in the rate of relapse after RIC CBT. Comparisons between RIC and myeloablative CBT are under study with respect to survival, optimal cell dose, incidence of GVHD, and rate of infection.

\section{Progress in CB banking}

The banking process should be standardized for HLA testing, virus detection, and counting of CD34+ cells. A larger inventory of high quality $\mathrm{CB}$ units will allow the discovery of larger and better matched units.

\section{Designer baby}

In 1999, using preimplantation genetic diagnosis and in vitro fertilization techniques, embryos HLA-identical to an FA patient, but unaffected by FA, were selected for intrauterine transfer. The transfer of a single preselected embryo resulted in a full-term pregnancy. The patient underwent transplantation with her newborn sibling donor's HLA-identical CB. Currently, the patient is well and shows normal hematopoiesis ${ }^{24}$. Preselection of embryos not affected by a specific disease are technically feasible; however, ethical and legal issues should be discussed before wider application.

\section{Conclusion}

Unrelated CB has emerged as an alternative allogeneic stem cell source. $\mathrm{CB}$ is readily available and provides suitable HLA-matched donors for patients who require allogeneic transplantation. CBT provides timely transplantation for patients with an unstable disease and reduces risk of GVHD without increased risk of relapse. In the 
clinical reports of CBT, the survival rates were comparable between transplants from $\mathrm{CB}$ and unrelated $\mathrm{PBPC}$ or $\mathrm{BM}$ in children with acute leukemia. The low incidence of chronic GVHD in CBT may benefit the quality of life of long-term survivors. Despite the limited cell dose in adult CBT, it is expected that reduced GVHD in CBT may reduce the TRM. Patients who do not have a matched sibling donor should simultaneously search for unrelated adult donors and CB. CBT is recommended, when the transplantation is urgent and a CB unit of nucleated cells of more than $2.0 \times 10^{7} / \mathrm{kg}$ is available. With the rapid development in the field of $\mathrm{CBT}$ including biology of $\mathrm{CB}$, clinical trials, and banking process of $\mathrm{CB}$, future research will amplify the broad applications of $\mathrm{CB}$ and help greater numbers of future patients.

\section{Acknowledgment}

This study was supported by a grant from the National R\&D Program Cancer Control, Ministry for Health, Welfare and Family affairs, Republic of Korea (0520290).

\section{References}

1. Broxmeyer HE, Douglas GW, Hangoc G, Cooper S, Bard J, English D, et al. Human umbilical cord blood as a potential source of transplantable hematopoietic stem/progenitor cells. Proc Natl Acad Sci U S A 1989;86: 3828-32.

2. Gluckman E, Broxmeyer HA, Auerbach AD, Friedman HS, Douglas GW, Devergie A, et al. Hematopoietic reconstitution in a patient with Fanconi's anemia by means of umbilical-cord blood from an HLAidentical sibling. N Engl J Med 1989;321:1174-8.

3. Kurtzberg J, Laughlin M, Graham ML, Smith C, Olson JF, Halperin EC, et al. Placental blood as a source of hematopoietic stem cells for transplantation into unrelated recipients. N Engl J Med 1996;335:157-66.

4. Szabolcs P, Niedzwiecki D. Immune reconstitution after unrelated cord blood transplantation. Cytotherapy 2007;9:111-22.

5. Gardiner CM, Meara AO, Reen DJ. Differential cytotoxicity of cord blood and bone marrow-derived natural killer cells. Blood 1998;91:20713.

6. Tse W, Laughlin MJ. Umbilical cord blood transplantation: a new alternative option. Hematology Am Soc Hematol Educ Program 2005:37783.

7. Rocha V, Wagner JE Jr, Sobocinski KA, Klein JP, Zhang MJ, Horowitz MM, et al. Graft-versus-host disease in children who have received a cord-blood or bone marrow transplant from an HLA-identical sibling. Eurocord and International Bone Marrow Transplant Registry Working Committee on Alternative Donor and Stem Cell Sources. N Engl J Med 2000;342:1846-54.

8. Eapen M, Rubinstein P, Zhang MJ, Stevens C, Kurtzberg J, Scaradavou A, et al. Outcomes of transplantation of unrelated donor umbilical cord blood and bone marrow in children with acute leukaemia: a comparison study. Lancet 2007;369:1947-54.
9. Atsuta Y, Suzuki R, Nagamura-Inoue T, Taniguchi S, Takahashi S, Kai $S$, et al. Disease-specific analyses of unrelated cord blood transplantation compared with unrelated bone marrow transplantation in adult patients with acute leukemia. Blood 2009;113:1631-8..

10. Eapen M, Rocha V, Sanz G, Scaradavou A, Zhang MJ, Arcese W, et al. Effect of graft source on unrelated donor haemopoietic stem-cell transplantation in adults with acute leukaemia: a retrospective analysis. Lancet Oncol 2010;11:653-60.

11. Lee YH, Cho NC, Je KH, Han H, Han JY, Kim JS, et al. Successful sibling cord blood stem cell transplantation for relapsed acute mixed lineage leukemia. Korean J Hematol 1999;34:471-6.

12. Kang HJ, Yoo KH, Lee JW, Kim H, Lee SH, Sung KW, et al. Double umbilical cord blood transplantation for children and adolescents. Ann Hematol 2010;89:1035-44.

13. Yoo KH, Lee SH, Sung KW, Koo HH, Chung NG, Cho B, et al. Current status of pediatric umbilical cord blood transplantation in Korea: a multicenter retrospective analysis of 236 cases. Am J Hematol 2011;86:127.

14. Barker JN, Weisdorf DJ, DeFor TE, Blazar BR, McGlave PB, Miller JS, et al. Transplantation of 2 partially HLA-matched umbilical cord blood units to enhance engraftment in adults with hematologic malignancy. Blood 2005;105:1343-7.

15. Yoo KH, Lee SH, Kim HJ, Sung KW, Jung HL, Cho EJ, et al. The impact of post-thaw colony-forming units-granulocyte/macrophage on engraftment following unrelated cord blood transplantation in pediatric recipients. Bone Marrow Transplant 2007;39:515-21.

16. Kelly SS, Sola CB, de Lima M, Shpall E. Ex vivo expansion of cord blood. Bone Marrow Transplant 2009;44:673-81.

17. Pecora AL, Stiff P, Jennis A, Goldberg S, Rosenbluth R, Price P, et al. Prompt and durable engraftment in two older adult patients with high risk chronic myelogenous leukemia (CML) using ex vivo expanded and unmanipulated unrelated umbilical cord blood. Bone Marrow Transplant 2000;25:797-9.

18. Lee MW, Jang IK, Yoo KH, Sung KW, Koo HH. Stem and progenitor cells in human umbilical cord blood. Int J Hematol 2010;92:45-51.

19. Devine SM, Bartholomew AM, Mahmud N, Nelson M, Patil S, Hardy W, et al. Mesenchymal stem cells are capable of homing to the bone marrow of non-human primates following systemic infusion. Exp Hematol 2001;29:244-55.

20. Nauta AJ, Fibbe WE. Immunomodulatory properties of mesenchymal stromal cells. Blood 2007;110:3499-506.

21. Ball LM, Bernardo ME, Roelofs H, Lankester A, Cometa A, Egeler $\mathrm{RM}$, et al. Cotransplantation of ex vivo expanded mesenchymal stem cells accelerates lymphocyte recovery and may reduce the risk of graft failure in haploidentical hematopoietic stem-cell transplantation. Blood 2007;110:2764-7.

22. Lee SH, Cheuh HW, Yoo KH, Sung KW, Koo HH, Kim JY, et al. Cotransplantation of third party umbilical cord blood mesenchymal stem cells to promote engraftment in pediatric recipients of unrelated donor umbilical cord blood. Biol Blood Marrow Trnansplant 2011;17:S169-70.

23. Cutler C, Ballen K. Reduced-intensity conditioning and umbilical cord blood transplantation in adults. Bone Marrow Transplant 2009;44:66771.

24. Grewal SS, Kahn JP, MacMillan ML, Ramsay NK, Wagner JE. Successful hematopoietic stem cell transplantation for Fanconi anemia from an unaffected HLA-genotype-identical sibling selected using preimplantation genetic diagnosis. Blood 2004;103:1147-51. 